\title{
Effect of fractionated irradiation on the expression of multidrug resistance genes in the CNE1 human nasopharyngeal carcinoma cell line
}

\author{
XUE-NING JI ${ }^{1}$, FANG YANG ${ }^{1}$, XIAO-MEI SUI ${ }^{2}$, FU-GUANG WANG ${ }^{1}$, RI-GUANG GE $^{1}$, \\ XIU-LIAN QUAN ${ }^{1}$, TONG ZHAO ${ }^{1}$, BIN WEN GAO ${ }^{1}$ and RUO-YU WANG ${ }^{1}$ \\ ${ }^{1}$ Department of Oncology, Zhongshan Hospital, Dalian University, Dalian 116001; ${ }^{2}$ Department of Oncology, \\ The Affiliated Hospital of Weifang Medical College, Weifang 261000, P.R. China
}

Received June 6, 2012; Accepted September 20, 2012

DOI: $10.3892 / \mathrm{mmr} .2012 .1148$

\begin{abstract}
Nasopharyngeal carcinoma (NPC) often develops drug resistance following radiotherapy. The molecular basis of radiotherapy-related multidrug resistance (MDR) remains unclear. In the present study, we investigated the effect of fractionated irradiation on the expression of the MDR-1 gene and the MDR-associated protein P-glycoprotein (P-gp) in CNE1 human NPC cells. CNE1 cells were treated with fractionated X-rays. Drug resistance was determined by MTT assay. The expression levels of MDR-1 and P-gp were analyzed by RT-PCR and western blot analysis, respectively. Differential expression was analyzed by gene chips. The results revealed that low levels of mRNA expression of MDR1 were present in non-irradiated CNE1 cells. Compared with the control, the expression of MDR1 mRNA was gradually increased following fractionated irradiation. On day 21 , the expression of MDR1 mRNA was increased 1.59- and 2.19-fold, compared with the control, by treatment with 10 and $20 \mathrm{~Gy}$, respectively. We observed decreased MDR1 expression following treatment with 10 and $20 \mathrm{~Gy}$ irradiation on days 28 and 35, compared with day 21 . On days 21,28 and 35, expression was increased 1.37-, 1.40- and 1.15-fold by treatment with $20 \mathrm{~Gy}$ compared with $10 \mathrm{~Gy}$. Expression of MDR1 was significantly upregulated by treatment with 50 Gy irradiation compared with the control on days 78 and 106. P-gp expression was consistent with that of MDR1 mRNA expression. The sensitivity of CNE1 cells to cisplatin was reduced following irradiation compared with the control. A total of 26 genes were significantly upregulated and 8 genes were significantly downregulated compared with the control.
\end{abstract}

Correspondence to: Professor Ruo-Yu Wang, Department of Oncology, Zhongshan Hospital, Dalian University, Zhongshan Road No. 6, Dalian 116001, P.R. China

E-mail: wangruoyu473@126.com

Key words: nasopharyngeal carcinoma, radiation therapy, multidrug resistance gene, matrix metallopeptidase-7, Bcl-2
Results of the present study have shown that MDR1 and P-gp are upregulated in CNE1 cells following irradiation. Multiple genes were involved in the mechanism of radiation-induced drug resistance.

\section{Introduction}

Nasopharyngeal carcinoma (NPC) is one of the most common types of head and neck cancer in Asia, particularly in Southeast Asia and China (1). According to standards outlined by the American Joint Committee on Cancer Staging, more than $50 \%$ of NPC cases are advanced (2). Radiotherapy is a standard treatment utilized to improve patient survival rates (3). However, despite the majority of cases responding well to initial radiotherapy or concurrent chemotherapy (4-6), the development of drug resistance is known to occur, resulting in failure to cure the disease.

Multidrug resistance (MDR) is a phenomenon in which tumor cells acquire simultaneous resistance to a diverse group of cytotoxic drugs. MDR remains a major obstacle in cancer chemotherapy, and is observed in patients who have received prior radiotherapy, particularly those that have undergone repeated courses of chemotherapy $(7,8)$. Overexpression of $\mathrm{P}$-glycoprotein $(\mathrm{P}-\mathrm{gp})$ is associated with drug resistance and has been observed in cells of murine and human cell lines following irradiation $(9,10)$. However, there is little information on whether radiation promotes the development of drug resistance in NPC cells. The molecular basis of radiotherapyrelated MDR remains unclear.

The majority of in vitro studies of radiation-drug interactions have involved exposure of cells to single-dose radiation, despite the common use of fractionated irradiation in clinical radiotherapy. In the present study, the effect of various doses of fractionated irradiation on the the human nasopharyngeal cell line CNE1 was investigated. Expression of the membraneassociated protein P-gp and its corresponding gene, MDR1, was analyzed over various time points, and functional resistance to the cytotoxic drug cisplatin was also investigated. Following this, gene chips were used to gain insight into the molecular mechanisms associated with MDR induction by fractionated irradiation. 


\section{Materials and methods}

Cells and reagents. The human NPC cell line CNE1 was purchased from the Chinese Academy of Science Cell Bank (Beijing, China). Cells were maintained in RPMI-1640 medium with $10 \%$ fetal bovine serum (Thermo Scientific Hyclone, Logan, UT, USA) and were incubated at $37^{\circ} \mathrm{C}$ in a humidified atmosphere of $95 \%$ air and $5 \% \mathrm{CO}_{2}$.

Radiation and drug cytotoxicity assays. Cells growing exponentially in flasks were irradiated with a total dose of 10,20 or $50 \mathrm{~Gy}$. For the 10 and $20 \mathrm{~Gy}$ groups, five fractions of $2.0 \mathrm{~Gy} /$ week were administered. For the 50 Gy group, 2.0 Gy two days/week was administered. Irradiation was performed with a Varian 2300C/D linear accelerator (Varian, Darmstadt, Germany) using $6 \mathrm{MV} \mathrm{X}$-rays. Following irradiation, culture medium was removed and the cells were rinsed to remove floating dead cells. Cells were harvested each week from the beginning of irradiation until week 5 for the 10 and 20 Gy groups. For the 50 Gy group, cells were harvested each week following completion of irradiation until week 7. Cells were collected when the expression levels of MDR1 and P-gp were significantly increased compared with the control. Drug sensitivity assays were performed (11). A total of $1 \times 10^{5}$ cells in $0.2 \mathrm{ml} \mathrm{medium} /$ well were grown in 96-well culture plates and incubated with increasing concentrations of cisplatin for 3 days in culture (final concentration $50 \mu \mathrm{g} / \mathrm{ml}$ ). Cell viability relative to untreated control cells was determined using the MTT assay (12). The $50 \%$ inhibitory concentration $\left(\mathrm{IC}_{50}\right)$, defined as the drug concentration causing $50 \%$ reduction in cell viability, was calculated, and the relative drug resistance was calculated by dividing the $\mathrm{IC}_{50}$ for the irradiated $\mathrm{CNE} 1$ cells by the $\mathrm{IC}_{50}$ for the non-irradiated CNE1 cells. Experiments were run in triplicate.

$R N A$ preparation and reverse transcription (RT)-PCR Viable cells were harvested and resuspended in guanidium thiocyanate buffer and stored at $-80^{\circ} \mathrm{C}$. Total RNA extraction was performed using TRIzol reagent (Invitrogen, Grand Island, NY, USA) according to the manufacturer's instructions. Concentration and purity of RNA was assessed electrophoretically and quantified spectrophotometrically. cDNA was generated from $1 \mu \mathrm{g}$ total RNA by reverse transcription using a Reverse Transcription System kit (Takara, Tokyo, Japan). RT-PCR was performed as previously described (13), using the primer sequences listed in Table I. PCR products were size-fractioned and subjected to electrophoresis on $2 \%$ agarose gels. Products were visualized by staining with ethidium bromide. RNA integrity was confirmed by performing PCR amplification of each cDNA with primers for the reference gene glyceraldehyde 3-phosphate dehydrogenase (GAPDH; Life Technologies, Carlsbad, CA, USA). Preliminary experiments were carried out to determine the linear range of PCR amplification using representative cases. The PCR conditions in this study were as follows: MDR1, GAPDH, 2 min at $94^{\circ} \mathrm{C}$, followed by $30 \mathrm{sec}$ at $94^{\circ} \mathrm{C}, 30 \mathrm{sec}$ at $53^{\circ} \mathrm{C}$ and $1 \mathrm{~min}$ at $72^{\circ} \mathrm{C}$ for 35 cycles, followed by $72^{\circ} \mathrm{C}$ for $10 \mathrm{~min}$; Bcl-2, 3 min at $94^{\circ} \mathrm{C}$, followed by $30 \mathrm{sec}$ at $94^{\circ} \mathrm{C}, 30 \mathrm{sec}$ at $55^{\circ} \mathrm{C}$ and $30 \mathrm{sec}$ at $72^{\circ} \mathrm{C}$ for 30 cycles, followed by $72^{\circ} \mathrm{C}$ for $10 \mathrm{~min}$; MMP-7, $4 \mathrm{~min}$ at $94^{\circ} \mathrm{C}$, followed by $30 \mathrm{sec}$ at $94^{\circ} \mathrm{C}, 30 \mathrm{sec}$ at $59^{\circ} \mathrm{C}$ and
$30 \mathrm{sec}$ at $72^{\circ} \mathrm{C}$ for 33 cycles, followed by $72^{\circ} \mathrm{C}$ for $10 \mathrm{~min}$. PCR fragments were quantified using the ImageMaster gel analysis equipment (Amersham Pharmacia Biotech, Amersham, UK). Densitometric analysis was performed to determine to the relative mRNA expression levels of genes outlined in Table I.

Western blot analysis. Cells $\left(1 \times 10^{7}\right)$ were washed in phosphate-buffered saline (PBS; pH 7.2) and resuspended in $200 \mathrm{ml}$ lysis buffer $(50 \mathrm{mM}$ Tris, $150 \mathrm{mmol} / \mathrm{l} \mathrm{NaCl}, 5 \mathrm{mmol} / \mathrm{l}$ EDTA, 1\% Triton X-100, 1 mM PMSF, pH 8.0) and sonicated on ice. Membrane fractions for P-gp were prepared as previously described (14). The membrane pellet was resuspended in PBS, and the protein content was determined using the DC protein assay kit (Bio-Rad, Hercules, CA, USA). Membraneenriched fractions containing $100 \mu \mathrm{g}$ protein were separated on SDS-PAGE, followed by western blot analysis. Blots were probed using an antibody against P-gp (C219; Centocor, Malvern, PA, USA; 1:200). $\beta$-actin (sc-8432; Santa Cruz Biotechnology Inc., Santa Cruz, CA, USA) was used as an internal loading control. Proteins were detected using the chemiluminescent method and quantified using the Amersham ECL gel system (Amersham Pharmacia Biotech). All experiments were repeated at least once.

Analysis of $m R N A$ expression using $c D N A$ arrays. Relative mRNA expression levels of specific apoptosis- and proliferation-related genes were analyzed with a nonradioactively labeled cRNA on oligo GEArray series (Superarray, Warren, OR, USA), according to the manufacturer's instructions. Using the TrueLabeling-AMP Linear RNA amplification kit (Takara), mRNA was reverse transcribed to obtain cDNA and converted into biotin-labeled cRNA using biotin-16-UTP (Roche Diagnostics, Mannheim, Germany) by in vitro transcription. Prior to hybridization, the cRNA probes were purified with the ArrayGrade cRNA cleanup kit (Superarray). Purified cRNA probes were hybridized to the pretreated Oligo GEArray Human Cancer Microarrays OHS-044 (Superarray), containing 128 genes associated with 15 signaling pathways. Following several washing steps, array spots binding cRNA were detected using alkaline phosphatase-conjugated streptavidin and CDP-Star as the chemiluminescent substrate. The image data were analyzed with the GEArray Expression Analysis Suite (Superarray). Following normalization to the signal of the housekeeping gene, the relative expression level of each gene was determined by comparing the signal intensity of each gene in the array. Arbitrary units were calculated as follows: (target gene signal - background signal)/(housekeeping gene - background signal). Data filtering criteria were as follows: at least one of the spot intensities to be compared had to be more than twice the background intensity, and the spot intensity ratios had to be $>2$ (for upregulation) or $<-2$ (for downregulation). Validation of array results was performed by RT-PCR.

Statistical analysis. Data were presented as the mean values $\pm \mathrm{SD}$. Multiple comparisons were initially subjected to one-way analysis of variance (ANOVA). Pairwise comparison between groups was analyzed by LSD test. The statistical analysis was performed using SPSS software 14.0. $\mathrm{P}<0.05$ was considered to indicate a statistically significant difference. 
Table I. Primer sequences in RT-PCR.

\begin{tabular}{lll}
\hline Gene & \multicolumn{1}{c}{ Primers/probe sequences } & Amplicon (bp) \\
\hline MDR1 & 5'-CCCATCATTGCAATAGCAGG- 3' (forward) & 157 \\
BCL-2 & 5'-GTTCAAACTTCTGCTCCTGA-3' (reverse) & 103 \\
& 5'-GGATTGTGGCCTTCTTGAG-3' (forward) & 239 \\
MMP-7 & 5'-CCAAACTGAGCAGAGTCTTC-3' (reverse) & 125 \\
GADPH & 5'-AAAATGCCAACAGTTTAGAAGC-3' (forward) \\
& 5'-CGTCCAGCGTTCATCCTC-3' (reverse) \\
\hline
\end{tabular}

A

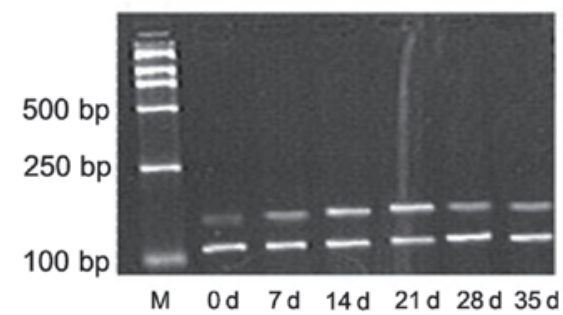

C

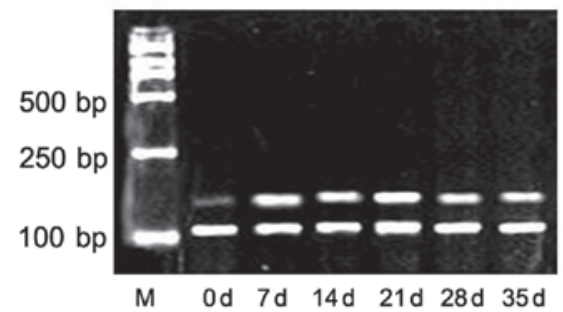

$\mathbf{E}$

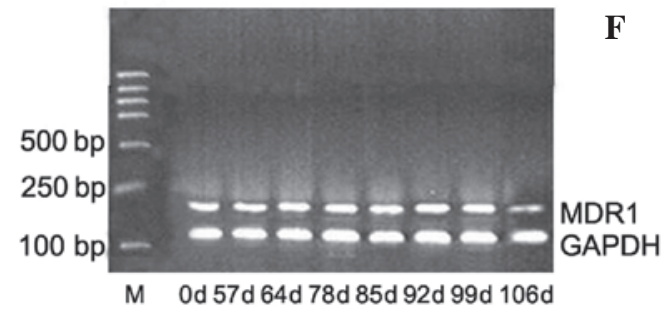

B

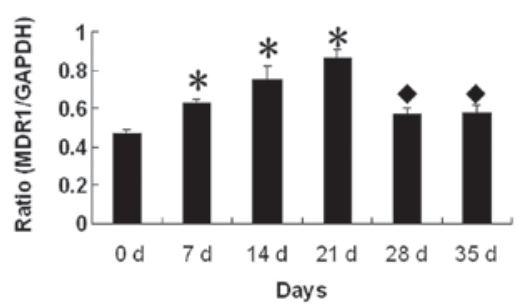

D
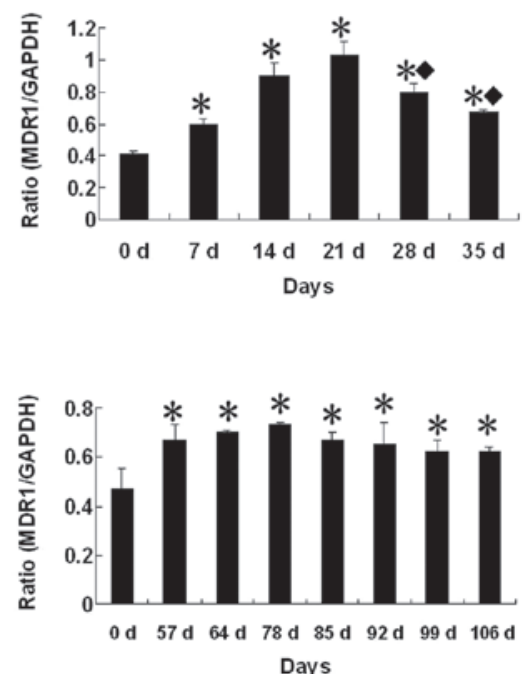

Figure 1. mRNA expression of MDR1 in CNE1 cells and irradiated CNE1 cells. Irradiated cells received a total dose of (A and B) 10 Gy, (C and D) 20 Gy and (E and F) 50 Gy for the indicated times. mRNA expression of MDR1 was measured by RT-PCR. The housekeeping gene GAPDH was used for normalization. Each experiment was run in triplicate. ${ }^{*} \mathrm{P}<0.05$, compared with control $\left(0\right.$ days); ${ }^{\bullet} \mathrm{P}<0.05$, compared with day 21 .

\section{Results}

Expression of MDRI mRNA following fractionated irradiation. CNE1 cells were treated with fractionated radiation with a cumulative dose of 10,20 or $50 \mathrm{~Gy}$, five fractions of $2 \mathrm{~Gy} /$ week for 10 and $20 \mathrm{~Gy}, 2$ Gy every two days/week for $50 \mathrm{~Gy}$. RT-PCR was performed to examine the correlation between radiation conditions and expression of the MDR gene, MDR1 (Fig. 1A, C and E). Low basal levels of MDR1 mRNA expression were identified in non-irradiated CNE1 cells. Compared with non-irradiated cells, the expression of MDR1 mRNA was gradually increased following fractionated irradiation. The largest increase in MDR1 expression levels was identified at day 21 for treatment with 10 and 20 Gy (1.59- and 2.19-fold, respectively, $\mathrm{P}<0.05$; Fig. $1 \mathrm{~B}$ and D). On days 28 and 35, MDR1 mRNA was decreased, but remained significantly higher than that in non-irradiated CNE1 cells. Treatment with 20 Gy yielded a 1.37-, 1.40- and 1.15-fold increase on days 21, 28 and 35 , respectively (all $\mathrm{P}<0.05$ ) compared with treatment with 10 Gy. MDR1 mRNA was studied following irradiation with a high dose of 50 Gy. Expression of MDR1 mRNA was significantly increased, and was detected until day 106. Expression of MDR1 mRNA was highest on day 78 (1.55-fold, $\mathrm{P}<0.05$; Fig. 1F). 
A

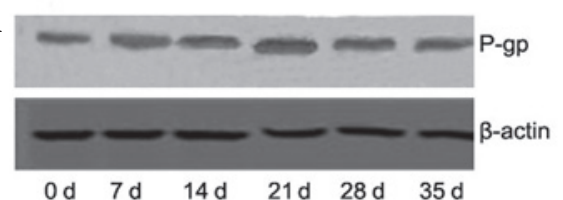

$\mathbf{B}$
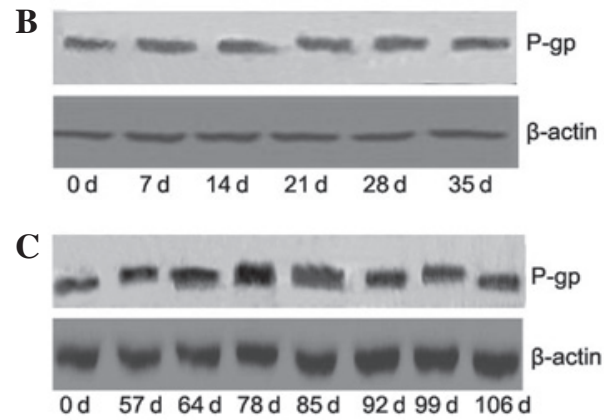

Figure 2. Protein expression of P-gp in CNE1 cells. Cells were treated with varying doses of irradiation. (A) $10 \mathrm{~Gy}$; (B) $20 \mathrm{~Gy}$; (C) 50 Gy. Protein expression of P-gp was analyzed by western blotting as described in Materials and methods. Representative blots are shown for each radiation dose. d, days.

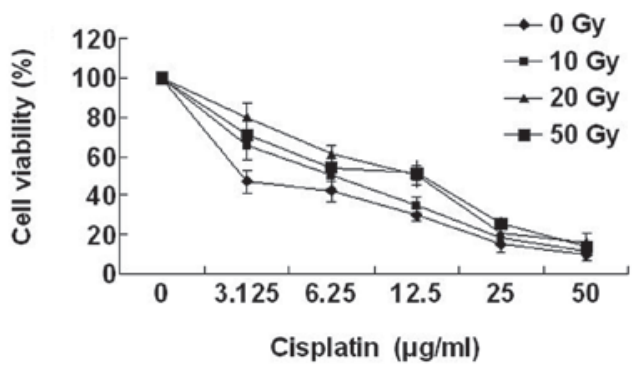

Figure 3. Drug sensitivity of non-irradiated and irradiated CNE1 cells. CNE1 cells were treated with doses of 10,20 or 50 Gy for 21 days. Cells in logphase growth in 96-well culture plates were treated with the indicated dose of cisplatin, after which their viability relative to untreated control cells was determined using the MTT assay. Mean and standard deviation of triplicate determinations are shown, and a representative experiment is presented.

Expression of P-gp following fractionated irradiation. Expression levels of the MDR1 gene protein product, P-gp, were assessed by western blot analysis. As shown in Fig. 2, the protein expression of $\mathrm{P}-\mathrm{gp}$ was consistent with that of MDR1 mRNA expression. On day 21, protein levels of P-gp were significantly increased by 1.86 - and 2.25 -fold compared with control, following treatment with 10 and 20 Gy radiation, respectively (all $\mathrm{P}<0.05$ ). Treatment with 20 Gy produced a 1.21-, 1.47- and 1.25-fold increase, compared with treatment with 10 Gy radiation, on days 21,28 and 35 , respectively (all $\mathrm{P}<0.05$ ). On day 78, the protein expression of $\mathrm{P}$-gp was increased 1.74-fold $(\mathrm{P}<0.05)$ compared with the control, following treatment with a high dose of $50 \mathrm{~Gy}$ radiation.

Drug sensitivity of the CNE1 cell line following irradiation. Drug cytotoxicity curves obtained in the irradiated and nonirradiated CNE1 cells are presented in Fig. 3. Cisplatin was selected for this study on the basis of sensitivity of NPC to the cytotoxic agent. Sensitivity of CNE1 cells to cisplatin was reduced following irradiation, compared with the control. Compared with the median viability of non-irradiated cells, a significant increase in the median viability of the irradiated

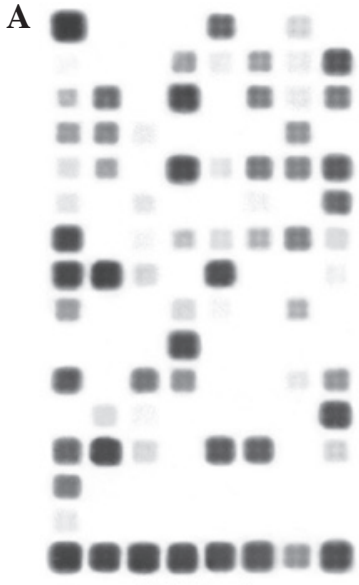

CNE1 cells

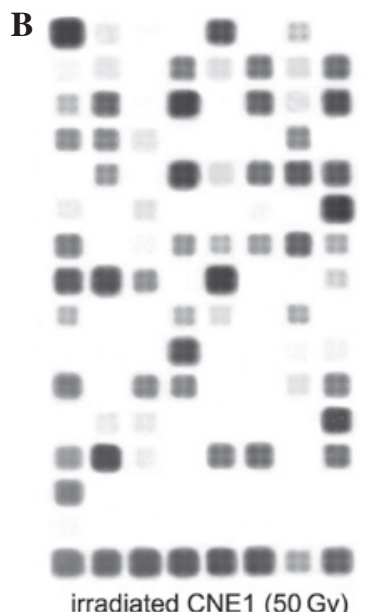

irradiated CNE1 (50 Gy)
Figure 4. Irradiation regulates the expression of multiple genes at the mRNA level. Microarray experiments was performed in (A) CNE1 cells and (B) irradiated CNE1 cells treated with 50 Gy irradiation for 78 days. In total, 128 genes are contained on the Oligo GEArray Human Cancer Microarray OHS-044.

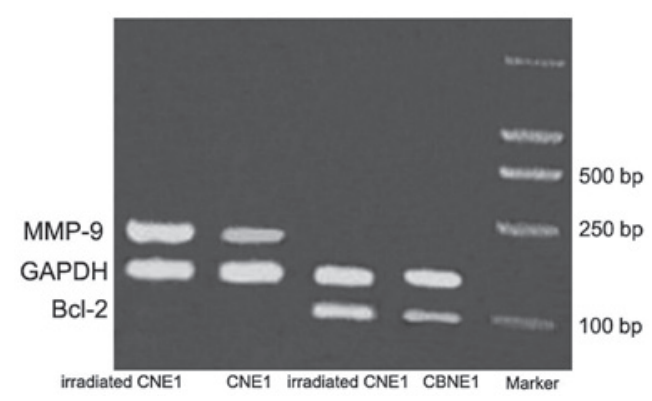

Figure 5. Verification of altered gene expression in CNE1 cells by quantitative RT-PCR. Altered expression of genes in the microarray were corroborated by PCR. Change in gene expression in irradiated CNE1 cells compared with nonirradiated CNE1 cells is shown.

cells for $10 \mathrm{~Gy}$ (2.08-fold), $20 \mathrm{~Gy}$ (4.15-fold) and $50 \mathrm{~Gy}$ (4-fold; all $\mathrm{P}<0.05$ ) was identified.

Irradiation regulates the expression of multiple genes at the $m R N A$ level. In order to test the hypothesis that exposure to irradiation induces gene expression changes in signaling pathways associated with cancer, CNE1 cells treated with $50 \mathrm{~Gy}$ irradiation at day 78 were analyzed by microarray. Following irradiation of the 128 genes contained on the Oligo GEArray Human Cancer Microarray OHS-044 (Fig. 4), 26 genes were upregulated and 8 were downregulated according to the selected filter criteria (Tables II and III). These genes comprised a variety of oncological groups associated with cellular functions, including cell stress, inflammation, adhesion and cell death, suggesting a functional role of irradiation in these processes. To further quantify gene expression levels in cells used in the microarray, we selected genes associated with proliferation and apoptosis (BCL-2 and MMP-7) and performed further analysis by RT-PCR (Fig. 5).

\section{Discussion}

In the present study, our first objective was to confirm whether irradiation induces the upregulation of MDR1 mRNA and 
Table II. List of the 26 genes with upregulated expression in irradiated CNE1 cells compared with non-irradiated CNE1 cells.

Gene Bank accession number Symbol
Irradiated CNE1/ CNE1

\begin{tabular}{|c|c|c|c|}
\hline NM_000014 & $\mathrm{A} 2 \mathrm{M}$ & $\alpha$-2-macroglobulin & 7.6606850 \\
\hline NM_000927 & $\mathrm{ABCB} 1$ & ATP-binding cassette & 5.9007979 \\
\hline NM_000633 & BCL2 & B-cell CLL/lymphoma 2 & 3.3802493 \\
\hline NM_199173 & BGLAP & Bone $\gamma$-carboxyglutamate (gla) protein (osteocalcin) & 2.4023970 \\
\hline NM_001165 & BIRC3 & Baculoviral IAP repeat-containing 3 & 2.3226417 \\
\hline NM_000089 & COL1A2 & Collagen, type I, $\alpha 2$ & 2.2922554 \\
\hline NM_000799 & EPO & Erythropoietin & 2.6616851 \\
\hline NM_000043 & FAS & Fas (TNF receptor superfamily, 6) & 2.4901347 \\
\hline NM_004476 & FOLH1 & Folate hydrolase 1 & 2.6467973 \\
\hline NM_022475 & HMOX1 & Heme oxygenase (decycling) 1 & 2.3548339 \\
\hline NM_002133 & HSPA4 & Heat shock $70-\mathrm{kDa}$ protein 4 & 2.9072737 \\
\hline NM_002154 & HSPA5 & Heat shock $70-\mathrm{kDa}$ protein 5 & 3.9989408 \\
\hline NM_005347 & ICAM1 & Intercellular adhesion molecule 1 & 3.6120906 \\
\hline NM_000201 & ID2 & Inhibitor of DNA binding 2, dominant negative helix-loop-helix protein & 2.3307183 \\
\hline NM_002166 & IL4 & Interleukin 4 & 6.1478924 \\
\hline NM_000589 & IRF1 & Interferon regulatory factor 1 & 2.242845 \\
\hline NM_002198 & KLK2 & Kallikrein-related peptidase 2 & 11.837389 \\
\hline NM_005551 & MDM2 & Mdm2, transformed 3T3 cell double minute 2, p53 binding protein & 4.7794018 \\
\hline NM_002392 & MMP7 & Matrix metallopeptidase 7 & 9.8154842 \\
\hline NM_002423 & MT3 & Metallothionein 3 & 6.4771969 \\
\hline NM_005954 & NOS2A & Nitric oxide synthase $2 \mathrm{~A}$ & 2.8604777 \\
\hline NM_000625 & PECAM1 & Platelet/endothelial cell adhesion 1 & 23.512991 \\
\hline NM_000442 & TCF7 & Transcription factor 7 & 2.6215746 \\
\hline NM_003202 & $\mathrm{TF}$ & Transferrin & 2.0762113 \\
\hline NM_001063 & TNFSF10 & Tumor necrosis factor (ligand) superfamily, member 10 & 2.2066475 \\
\hline NM_003810 & TP53 & Tumor protein $\mathrm{p} 53$ & 3.4717765 \\
\hline
\end{tabular}

Table III. List of the 8 genes with downregulated expression in irradiated CNE1 cells compared with non-irradiated CNE1 cells.

Gene Bank accession number
Symbol

Description

$\begin{array}{lll}\text { CTNNB1 } & \text { Catenin, } \beta \text { 1, 88 kDa } & 0.237207 \\ \text { KLK3 } & \text { Kallikrein-related peptidase 3 } & 0.215753 \\ \text { LTA } & \text { Lymphotoxin } \alpha & 0.178995 \\ \text { NAIP } & \text { NLR family, apoptosis inhibitory protein } & 0.02121 \\ \text { PTCH1 } & \text { Patched homolog 1 (Drosophila) } & 0.424597 \\ \text { TMEPAI } & \text { Transmembrane, prostate androgen induced RNA } & 0.487702 \\ \text { TNF } & \text { Tumor necrosis factor } & 0.265229 \\ \text { WSB1 } & \text { WD repeat and SOCS box-containing } & 0.4685042\end{array}$

P-gp in CNE1 cells. Unlike previous studies, the aim of the present study was to detect changes in the expression levels of MDR1 and P-gp at higher accumulative doses of irradiation, which are more relevant to clinical protocols. In addition, the molecular mechanisms of drug resistance were studied, using microarray experiments.

We identified a limited expression of MDR1 mRNA and P-gp in untreated CNE1 cells, supporting previous studies which reported that the expression of MDR1 mRNA and $\mathrm{P}-\mathrm{gp}$ was of minor relevance to intrinsic therapy resistance of cancer (15). Expression of MDR1 mRNA and P-gp initially increased and then decreased following irradiation in a timedependent manner. However, expression levels in irradiated CNE1 cells were always higher than that of non-irradiated cells. CNE1 cells treated by fractionated radiation with 10, 20 or 50 Gy became resistant to cisplatin, the main drug used 
to treat NPC. Development of resistance was correlated with the expression of MDR1 mRNA and protein. Overexpression of MDR1 has been previously reported to be associated with protection of normal tissues from radiation- or chemotherapyinduced damage during tumor treatment, by upregulation of the anti-apoptotic gene AKT3 (16). In addition, resistance of hematopoietic progenitors to cyclophosphamide was conferred by a high expression of MDR1, linking with increased transcription of ALDH1 (17).

Previous studies have reported that P-gp inhibits apoptosis by suppression of caspase activity. However, the nature of this interaction has not been identified (18). Furthermore, addition of a general caspase inhibitor has been demonstrated to increase clonogenic survival rate of TK6 cells following irradiation (19). An effect of P-gp on caspases has also been identified at the transcription level (16). Fractionated radiation treatment has also been reported to cause drug resistance in ovarian carcinoma cells $(9,20)$, Chinese hamster ovary (CHO) cells (20), ascites tumor cells (10), SCLC cells (21), breast cancer cell lines and colon cancer cell lines (22). In the absence of further treatment, no marked change with continuous culture for 56 days was identified, indicative of a stable resistant phenotype. The stability and 4-fold resistance to cisplatin exhibited by the CNE1 cells is indicative of the resistance phenotype associated with NPC. Our results suggest that fractionated radiation treatment alone may induce the development of drug resistance. Other reports of radiation treatment causing stable resistance to chemotherapeutic drugs in cancer cells have been published. These include a study in colon cancer cells, where durability of resistance was present for 18 days, following an irradiation dose of $27 \mathrm{~Gy}$ (23). In SCLC, a total dose of 37.5 Gy has been demonstrated to sustain durability of resistance for 6 months $(23,24)$. Our studies suggest a possible mechanism of P-gp enhancement, through an increase in protein half-life and stability or by upregulation of MDR1 gene expression.

However, radiation in MDR cells has also been demonstrated to mediate loss of extrachromosomally amplified MDR1 genes, concomitant with a reduction in P-gp levels (25). Fractionated irradiation led to the restoration of drug sensitivity by the downregulation of P-gp in MDR cells (26). Possible reasons for these observations are the heterogeneity of cells or low does of fractionated radiation (27).

Irradiation-induced stress response may affect cell cycle regulation, cellular differentiation, oncogenic transformation, cell survival and apoptosis (28). In order to understand the possible molecular mechanism of the radiation-induced MDR, a cancer microarray gene chip was utilized. Following irradiation, 26 genes were upregulated, indicating that drug resistance is associated with increased expression levels of a number of anti-apoptotic genes, including PECAM-1, ICAM-1, BCL-2, MMP-7, HSP70 and IL-4. For example, it is well known that overexpression of BCL-2 inhibits apoptosis and exhibits radioprotective properties $(29,30)$.

The largest increase in gene expression in irradiated cells compared with non-irradiated cells was identified in the gene PECAM-1 (23.5-fold). Another adhesion molecule, ICAM-1, was also upregulated. Endothelial cells express the heterotypic ligand $(\alpha v \beta 3)$ for PECAM1-CD31. Buckley et al speculated that CD31 homophilic and heterophilic adhesion could be involved in a signaling mechanism that regulated endothelial cell proliferation and differentiation (31). Therefore, as a general response to irradiation, CD31 upregulation may disrupt this regulatory balance and hinder the ability of the vasculature to recover from radiation damage, potentially causing abnormal cell proliferation. Further studies are required to determine whether CD31 could function as a promising therapeutic target $(32,33)$. Additional studies have demonstrated the upregulation of ICAM-1 in rat liver following irradiation (34), indicative of a significant role in radiation-induced lung injury in patients with lung cancer (35).

MMP-7, another upregulated gene, has been linked with tumor invasion and metastasis. MMP-7 expression in tumor cell lines resulted in loss of responsiveness to chemotherapeutic agents $(36,37)$. Chronic exposure to MMP-7 acted as a selective pressure for apoptotic resistance, through the generation of a chronic Fas-activating signal. This resulted in alteration of the apoptosis signaling pathway, leading to loss of sensitivity to various death stimuli (38-40). Mitsiades et al (37) demonstrated one mechanism whereby MMP-7 promotes tumor survival rate and resistance to doxorubicin through cleavage of FasL. Proteolysis of the ligand was found to reduce its effectiveness in triggering Fas-mediated apoptosis (41). Insulin-like growth factor-1 (IGF-I) bioavailability has been demonstrated to be regulated by MMP-7 proteolysis of IGFBP-3, leading to the promotion of cell survival (42).

Previously, IL-4 was associated with survivin expression and localization, through activation of the STAT6 signaling pathway (43), and decrease of apoptosis in HCT116 colon cancer cells (44).These results have shed more light on the molecular mechanisms involved in IL-4-mediated chemoresistance.

Heat shock proteins (HSPs) are a super family of highly conserved molecular chaperone proteins, which are induced in response to stress. HSP70 has been demonstrated to inhibit apoptosis induced by a number of chemotherapeutic agents. HSP70 inhibitors enhanced melphalan-induced apoptosis and reversed melphalan-induced cell adhesion-mediated drug resistance phenotype (45). High-dose radiation upregulated the expression of HSPB1 and particularly HSP70. These results suggest that HSP70 is a key molecule in the induction of the adaptive response (46).

Although Fas and p53 were upregulated, a balance between the expression of these functionally antagonistic proteins is thought to determine whether a cell survives or undergoes apoptosis. Radiation activated nitric oxide synthase production, which plays a role in the regulation of apoptosis. However, a cytoprotective role remains controversial (47). Other differentially expressed genes identified in the microarray, included $\alpha$-2-macroglobulin, folate hydrolase 1 and kallikrein-related peptidase 2 . These genes need to be studied further to confirm their correlation with MDR.

In conclusion, our study extended prior reports of radiation-induced MDR. Overexpression of MDR1 in cancer cells has been shown to protect against radiation-induced apoptosis and clonogenic cell death. Our results suggest that optimization of fractionated irradiation could lead to important considerations in the design of chemoradiation strategies against MDR cells. This study provides a good foundation for the confirmation of the specific molecular mechanism of radiation-induced MDR. 


\section{Acknowledgements}

This study was supported in part by a grant from the National Natural and Scientific Foundation of China, no. 30970869.

\section{References}

1. Smith C, Tsang J, Beagley L, et al: Effective treatment of metastatic forms of Epstein-Barr virus-associated nasopharyngeal carcinoma with a novel adenovirus-based adoptive immunotherapy. Cancer Res 72: 1116-1125, 2012.

2. Hughes J, Alusi G and Wang Y: Gene therapy and nasopharyngeal carcinoma. Rhinology 50: 115-121, 2012.

3. Sun Y, Tang LL, Chen L, et al: Promising treatment outcomes of intensity-modulated radiation therapy for nasopharyngeal carcinoma patients with N0 disease according to the seventh edition of the AJCC staging system. BMC Cancer 12: 68, 2012.

4. Zhang $X$ and Li W: 5-Fluorouracil in combination with cisplatin alters the microRNA expression profile in the CNE nasopharyngeal carcinoma cell line. Mol Med Rep 6: 303-308, 2012 .

5. Ma BB and Chan AT: Recent perspectives in the role of chemotherapy in the management of advanced nasopharyngeal carcinoma. Cancer 103: 22-31, 2005.

6. Komatsu M, Tsukuda M, Matsuda H, et al: Comparison of concurrent chemoradiotherapy versus induction chemotherapy followed by radiation in patients with nasopharyngeal carcinoma. Anticancer Res 32: 681-686, 2012.

7. Bansal T, Jaggi M, Khar RK and Talegaonkar S: Emerging significance of flavonoids as P-glycoprotein inhibitors in cancer chemotherapy. J Pharm Pharm Sci 12: 46-78, 2009.

8. Chang JW, Yu YS, Kim JY, et al: The clinical outcomes of proton beam radiation therapy for retinoblastomas that were resistant to chemotherapy and focal treatment. Korean J Ophthalmol 25 387-393, 2011

9. Delou JM, Capella MA and Gattass CR: Betulinic acid does not modulate the activity of P-gp/ABCB1 or MRP1/ABCC1 in a non-tumoral renal cell line: Possible utility in multidrug resistance cancer chemotherapy. Mol Med Rep 2: 271-275, 2009

10. Nielsen D, Maare C,Eriksen J, et al: Expression of P-glycoprotein and multidrug resistance associated protein in Ehrlich ascites tumor cells after fractionated irradiation. Int J Radiat Oncol Biol Phys 51: 1050-1057, 2001.

11. Hofstetter B, Vuong V, Broggini-Tenzer A, et al: Patupilone acts as radiosensitizing agent in multidrug-resistant cancer cells in vitro and in vivo. Clin Cancer Res 11: 1588-1596, 2005.

12. Zhu H, Yu WJ, Le Y, et al: High glucose levels increase the expression of neurotrophic factors associated with $\mathrm{p}-\mathrm{p} 42 / \mathrm{p} 44$ MAPK in Schwann cells in vitro. Mol Med Rep 6: 179-184, 2012

13. Okumura N, Yoshida H, Nishimura Y, et al: Clobetasol synergistically diminishes Cizl expression with genistein in U937 cells. Mol Med Report 5: 567-569, 2012.

14. Chen M, Huang SL, Zhang XQ, et al: Reversal effects of pantoprazole on multidrug resistance in human gastric adenocarcinoma cells by down-regulating the V-ATPases/mTOR/ HIF-1 $\alpha / \mathrm{P}$-gp and MRP1 signaling pathway in vitro and in vivo. J Cell Biochem 113: 2474-2487, 2012

15. Berger W, Setinek U, Hollaus $\mathrm{P}$, et al: Multidrug resistance markers P-glycoprotein, multidrug resistance protein 1 , and lung resistance protein in non-small cell lung cancer: prognostic implications. J Cancer Res Clin Oncol 131: 355-363, 2005.

16. Maier P, Fleckenstein K, Li L, et al: Overexpression of MDR1 using a retroviral vector differentially regulates genes involved in detoxification and apoptosis and confers radioprotection. Radiat Res 166: 463-473, 2006.

17. Kohn FR and Sladek NE: Ex vivo treatment of murine splenocyte-supplemented bone marrow inocula with mafosfamide prior to allogeneic transplantation in an attempt to prevent lethal graft-versus-host disease without compromising engraftment. Immunopharmacol Immunotoxicol 10: 387-398, 1988.

18. Tainton KM, Smyth MJ, Jackson JT, et al: Mutational analysis of P-glycoprotein: suppression of caspase activation in the absence of ATP-dependent drug efflux. Cell Death Differ 11: 1028-1037, 2004.

19. Schäfer J, Bachtler J, Engling A, et al: Suppression of apoptosis and clonogenic survival in irradiated human lymphoblasts with different TP53 status. Radiat Res 158: 699-706, 2002.
20. Hill BT, Whelan RD, Hurst HC and McClean S: Identification of a distinctive P-glycoprotein-mediated resistance phenotype in human ovarian carcinoma cells after their in vitro exposure to fractionated X-irradiation. Cancer 73: 2990-2999, 1994.

21. Henness S, Davey MW, Harvie RM, et al: Changes in gene expression associated with stable drug and radiation resistance in small cell lung cancer cells are similar to those caused by a single X-ray dose. Radiat Res 161: 495-503, 2004.

22. Bottke D, Koychev D, Busse A, et al: Fractionated irradiation can induce functionally relevant multidrug resistance gene and protein expression in human tumor cell lines. Radiat Res 170: 41-48, 2008.

23. Park JJ, Yi JY, Jin YB, et al: Sialylation of epidermal growth factor receptor regulates receptor activity and chemosensitivity to gefitinib in colon cancer cells. Biochem Pharmacol 83: 849-857, 2012

24. Grandjean F, Brémaud L, Verdier M, et al: Sequential gene expression of $\mathrm{P}$-glycoprotein (P-gp), multidrug resistanceassociated protein (MRP) and lung resistance protein: functional activity of P-gp and MRP present in the doxorubicin-resistant human K562 cell lines. Anticancer Drugs 12: 247-258, 2001.

25. Trussardi-Regnier A, Millot JM, Gorisse MC, et al: Detection of drug-resistance genes using single bronchoscopy biopsy specimens. Oncol Rep 18: 703-708, 2007.

26. Ryu JS, Um JH, Kang CD, et al: Fractionated irradiation leads to restoration of drug sensitivity in MDR cells that correlates with down-regulation of P-gp and DNA-dependent protein kinase activity. Radiat Res 162: 527-535, 2004.

27. Shareef MM, Brown B, Shajahan S, et al: Lack of P-glycoprotein expression by low-dose fractionated radiation results from loss of nuclear factor-kappaB and NF-Y activation in oral carcinoma cells. Mol Cancer Res 6: 89-98, 2008.

28. McAllister KA, Lorimore SA, Wright EG and Coates PJ: In vivo interactions between ionizing radiation, inflammation and chemical carcinogens identified by increased DNA damage responses. Radiat Res 177: 584-593, 2012.

29. Chen Z, Chua CC, Ho YS, et al: Overexpression of Bcl-2 attenuates apoptosis and protects against myocardial I/R injury in transgenic mice. Am J Physiol Heart Circ Physiol 280: H23132320,2001

30. Langenau DM, Jette C, Berghmans S, et al: Suppression of apoptosis by bcl-2 overexpression in lymphoid cells of transgenic zebrafish. Blood 105: 3278-3285, 2005.

31. Buckley CD, Doyonnas R, Newton JP, et al: Identification of alpha v beta 3 as a heterotypic ligand for CD31/PECAM-1. J Cell Sci 109: 437-445, 1996

32. Dangerfield JP, Wang S and Nourshargh S: Blockade of alpha6 integrin inhibits IL-1beta- but not TNF-alpha-induced neutrophil transmigration in vivo. J Leukoc Biol 77: 159-165, 2005.

33. Riederer I, Sievert W, Eissner G, et al: Irradiation-induced up-regulation of HLA-E on macrovascular endothelial cells confers protection against killing by activated natural killer cells. PLoS One 5: e15339, 2010.

34. Moriconi F, Malik I, Ahmad G, et al: Effect of irradiation on gene expression of rat liver adhesion molecules: in vivo and in vitro studies. Strahlenther Onkol 185: 460-468, 2009.

35. Liu Y, Yu H, Zhang C, et al: Protective effects of berberine on radiation-induced lung injury via intercellular adhesion molecular-1 and transforming growth factor-beta-1 in patients with lung cancer. Eur J Cancer 44: 2425-2432, 2008.

36. Hashimoto H, Takeuchi T, Komatsu K, et al: Structural basis for matrix metalloproteinase-2 (MMP-2)-selective inhibitory action of $\beta$-amyloid precursor protein-derived inhibitor. J Biol Chem 286: 33236-33243, 2011

37. Mitsiades N, Yu WH, Poulaki V, et al: Matrix metalloproteinase7-mediated cleavage of Fas ligand protects tumor cells from chemotherapeutic drug cytotoxicity. Cancer Res 61: 577-581, 2001.

38. Ohno S, Inagawa H, Dhar DK, et al: Role of tumor-associated macrophages (TAM) in advanced gastric carcinoma: the impact on FasL-mediated counterattack. Anticancer Res 25: 463-470, 2005.

39. Holler N, Tardivel A, Kovacsovics-Bankowski M, et al: Two adjacent trimeric Fas ligands are required for Fas signaling and formation of a death-inducing signaling complex. Mol Cell Biol 23: $1428-1440,2003$

40. Fingleton B, Vargo-Gogola T, Craw ford HC and Matrisian LM: Matrilysin [MMP-7] expression selects for cells with reduced sensitivity to apoptosis. Neoplasia 3: 459-468, 2001. 
41. Alla V, Kashyap A, Gregor S, et al: Human leukocyte elastase counteracts matrix metalloproteinase-7 induced apoptosis resistance of tumor cells. Cancer Lett 268: 331-339, 2008.

42. Miyamoto S, Yano K, Sugimoto S, et al: Matrix metalloproteinase-7 facilitates insulin-like growth factor bioavailability through its proteinase activity on insulin-like growth factor binding protein 3. Cancer Res 64: 665-671, 2004.

43. Di Stefano AB, Iovino F, Lombardo Y, et al: Survivin is regulated by interleukin-4 in colon cancer stem cells. J Cell Physiol 225: $555-561,2010$.

44. Koller FL, Hwang DG, Dozier EA and Fingleton B: Epithelial interleukin-4 receptor expression promotes colon tumor growth. Carcinogenesis 31: 1010-1027, 2010
45. Nimmanapalli R, Gerbino E, Dalton WS, et al: HSP70 inhibition reverses cell adhesion mediated and acquired drug resistance in multiple myeloma. Br J Haematol 142: 551-561, 2008.

46. Kang CM, Park KP, Cho CK, et al: Hspa4 (HSP70) is involved in the radioadaptive response: results from mouse splenocytes. Radiat Res 157: 650-655, 2002.

47. Liu W and Wu S: Differential roles of nitric oxide synthases in regulation of ultraviolet B light-induced apoptosis. Nitric Oxide 23: $199-205,2010$ 